\title{
Germination Responses of Several Poaceae Members towards Differential Storage Durations
}

\author{
Krishna R. PANCHAL*, Neeta R. PANDYA, Susy ALBERT, Dhara J. GANDHI \\ The Maharaja Sayajirao University of Baroda, Faculty of Science, Department of Botany, Vadodara-390 \\ 002, Gujarat,India; panchal_krishna@yahoo.com ( ${ }^{*}$ corresponding author)
}

\begin{abstract}
Concerns over biodiversity loss and increasing biological invasion have forced interest on assessment of the effects on native plant species diversity in grassland community. To observe different patterns of grass emergence (dormancy/germination) in the warm tropical grasslands of India, time span of a seed from the seedling stage to a mature plant becomes very crucial for the community development. In the present study seed germination response of six dominant species of the selected study area were tested to record the various effects of dry storage conditions on seed germinability. The species selected were Apluda mutica L., Cenchrus ciliaris L., Chrysopogon fulvus (Spreng.) Chiov., Dichanthium annulatum (Forsk.) Stapf., Heteropogon contortus (L.) P. Beauv. ex Roem. and Schult. and Themeda triandra (R. Br.) Stapf. For this purpose, seed collection at mature seed stage, seed processing and dry seed storage were followed by the germination test system. Obtained results are exhibited in the form of different responses such as, species response patterns towards capacity for immediate germination, responses to dormancy, dry storage and temperature fluctuation. The extent of the requirement in breakage of primary dormancy was highly correlated with the timing of seed maturity, precursors of seed dormancy and seed viability. In present screening out of the six studied species Apluda mutica, Cenchrus ciliaris and Dichanthium annulatum showed dependable germination pattern to fluctuating temperature. The correlation between viability and germination suggests that the germination of Apluda mutica, Cenchrus ciliaris and Themeda triandra are linearly dependent on the viability that the seeds of these species have. As these species showed less influence with the relative fluctuating environment, they can be stored for longer period and frequently can be use for community regeneration in pasture development.
\end{abstract}

Keywords: dormancy, germination, grasses, grassland community, temperature fluctuation

\section{Introduction}

The seedling stage of a plant's life is the most vulnerable by environmental risks and is usually accompanied by extremely high mortality. Thus, the plant demography becomes a fundamental to an understanding of both the ecological forces which shape plant population structure and the evolutionary forces which shape life history characteristic. The seedling and juvenile phases are of particular importance because the heavy mortality which is often observed in these phases may represent a major component of the selection operating in the plant life cycle (Silvertown and Dickie, 1981). Although it is always very difficult to determine the direct causes of seedling death in individual cases, biotic factors, such as predation and disease, and abiotic factors (desiccation) often play important roles in this high level of mortality. Since all these factors show seasonal variation in most habitats of tropical regions, the choice of the season for seedling emergence would be essential for increasing the probability of their successful establishment. To decide season of emergence, seeds may utilize certain types of environmental control of dormancy and/ or germination. The relative importance of each of three principal environmental factors controlling seed germination, i.e. light, moisture and temperature, in season choice mechanisms would vary with the types of ecosystems and habitats. Among which high moisture requirement of the seed for germination could be the major factor limiting germination especially during the dry season (Tomado $e t$ al., 2002). In habitats seasonal availability of water limits biological activities, rainfall heavier or lesser than a certain threshold level has been demonstrated to serve as a signal for seed germination. In many tropical regions with predictable annual variation in thermal environment, changes in temperature would provide the most reliable seasonal signals for seeds located at or near the soil surface. Various physiological mechanisms have been demonstrated or suggested to be responsible for seedling emergence seasonality: dormancy induction or breakage by certain ranges of temperature; limiting temperatures for the germination of non-dormant seeds; temperature dependency of the rate of germination (Baskin and Baskin, 1985).

In the present study, a germination response of few grass species was conducted. These grass species are dominantly found in the selected study area, situated in Gujarat, India. It stretches from Godhra to Dahod at the eastern edge of the state and situated at 147-164 m elevation (22 $50^{\circ}$ '$22^{\circ} 51^{\prime}$ N, 7342'-7343' E). Apluda mutica L. (Mauritian grass), Cenchrus ciliaris L. (Buffel grass), Chrysopogonfulvus (Spreng.) Chiov. (Golden beard grass), Dichanthium an- 
nulatum (Forsk.) Stapf (Kleberg's bluestem), Heteropogon contortus (L.) P. Beauv. ex Roem. and Schult. (Black spear grass) and Themeda triandra (R. Br.) Stapf. (Kangaroo grass) are the primary dominant grass species of the study area and is known as Bandheli Grassland. These species occur in varying proportions and are joined by other grasses, depending on macro and micro climatic conditions. The grasslands in the eastern part of India, essentially natural grasslands but the monsoon grasslands too, which show their best potential for the monsoon period only for about four months a year. After these four months owing to moisture stress and advent of winter, the grass species enter to the dormancy period till the next monsoon.

The studies on germination response were conducted by many authors with positive results. Jaiswal and Chaudhary (2005) tested germination behavior of trees and forage grasses by using different substrata; Beckstead et al. (1995) studied the after ripening effects on germination of Bromus tectorum and Elymus elymoides i.e. on viability basis; Andrews and Burrows (1972) check the germination response of Dormoat (derivatives of crosses between Avena sativa L. and A. fatua L.) dormant seeds towards low temperature; Karlsson et al. (2006) examined the pattern of germination and dormancy simultaneously for $\mathrm{Ga}$ leopsis speciosa.

In the selected grassland; continual usage of such excellent grasses and total dependency of nearby tribals for their cattles; resulted in the dwindling of proportion of these grasses. This dwindling; finally resulting in the influence of annual grasses and sometimes inferior and less palatable grasses also. Thus, such important reservoirs of forage require careful attention and scientific management.

In the present study, grass species' selection is based on their current usage pattern, requirement and dominance level in the grassland. Mentioned grass species is the most dominant and most widely naturally occurred pasture grasses. In the study area, availability of good quality seeds of such valuable grass species is the major constraint which limiting the increased production even by the Forest Department. To overcome such difficulties, an ecophysiological comparison of the mechanisms for deciding the season of emergence was performed with 6 grass species co-occurring in a dry tropical grassland community of eastern India, for which the phenologies for seed germination, seedling emergence and the storage effect on seed lot along with the seasonal variation are recorded. Based on the data obtained, responses of individual species, correlations of physiological mechanisms for the seedling emergence were analyzed.

\section{Materials and methods}

A screening of responses of germination has been carried out with the 6 grass species occurring in a selected grassland community in warm tropical region of India.
Seed collection, processing and seed storage for quality testing

The seeds of grass species listed in Tab. 1 were collected from the community at the peak of the seed dispersal season of the individual species. After the seeds had been air dried in a paper bag for about 1 month to facilitate post harvest ripening, they were thoroughly cleaned and processed. The germination responses of these prepared seeds were examined in a screening test without any kind of pretreatment up to 24 months. The test performed immediately after seed preparation without any pretreatment or storage was designated as the 'initial test'. The storage-type pretreatment was only the dry storage at laboratory condition in paper bags/plastic bottles; (temperature regimes according to seasons) for different time durations. Along with the germination responses according to storage capacity, other physiological parameters were also studied to get an exact idea for eco-physiological responses of seed.

\section{Germination test system}

100 seeds from each seed lot were placed under moist condition i.e. on filter papers moisten with $100 \mathrm{ml}$ of water in plastic trays $(35 \times 23 \times 6 \mathrm{~cm}$.). During the initial tests, seeds were placed on filter paper in each of two trays. The filter paper was moistened with distilled water and trays were transferred to a open laboratory condition i.e. available natural environmental conditions. During monsoon months the day-night temperature ranges between 25 $35^{\circ} \mathrm{C}$; during winter months it ranges between $20-35^{\circ} \mathrm{C}$ while during summer months this range fluctuates between $30-45^{\circ} \mathrm{C}$. During summer and winter months, due to full sunny days, light intensity available was high while during monsoon months because of cloudy weather available light intensity was low. Humidity range was between 50-89\% during monsoon months, $40-80 \%$ during winter months and during summer months it fluctuated between 75-115\% (All meteorological observations taken during experiment from Meteorological observatory situated in University campus). Each tray was inspected daily and germinated seeds were counted. The seed was considered to have germinated when the radicle and plumule both were emerged. The minimum duration of a test was 15 days and counting was continued until no further germination occurred for five successive days. Further successive tests were counted on subsamples removed from dry storage 2 , $4,6,8,10,12,14,16,18,20,22$ and 24 months after the seed collection. Along with it another eco-physiological parameter (viability by standard TTZ staining method (Peters, 2000) has also been examined.

The germination test system, which is a modification of the one reported previously (Washitani, 1987), uses a pair of temperature regimes (seasonally dependent). In one regime, seeds were stored at gradually increasing temperature in the range of $25-45^{\circ} \mathrm{C}$ (IT regime) i.e. from monsoon to summer period (November - April) and in the 
46

other, to a gradually decreasing temperature in the range of $25-30^{\circ} \mathrm{C}$ (DT regime) i.e. from winter to monsoon period (May - October). The percentage of germination attained immediately before the seeds were subjected to these last treatments was defined as the final percentage of germination of the regime and that after the last treatments as the maximum percentage of germination. The number of germinated seeds was recorded regularly at the interval of two days in each test. Whenever the mechanical dormancy was seen, it was broken by removal of seed covering structures. The influence of temperature and light upon germination percentage and rate was also studied.

\section{Results and discussion}

\section{Species response patterns}

A species response pattern in the present screening shows that seed collection per individual species was used to a variety of seed quality testing. Immediately after seed collection, all the seeds in this seed population were dormant, with no germination occurring in the initial test. Thus along with germination tests, other physiological parameters were examined to know exact reasons behind germination response to different storage durations. Great variations in the response patterns were observed among the species in the present screening, with no two species sharing the same response pattern. The main results of the tests are summarized in Tab. 1 .

The higher percentage of germination recorded in the test performed after the $2^{\text {nd }}$ and $4^{\text {th }}$ months of storage, indicating that somewhat higher temperatures were needed for a complete removal of primary dormancy. Exposure to a higher temperature range probably induced a secondary dormancy, since considerably lower percentages of germination were recorded during the DT regime in Chrysopogon fulvus and Themeda triandra. As the storage durations were increase, a least amount of relative dormancy was present in all species. Great variations in the response patterns to the temperature were observed among the species in the present screening. All the species shows their higher germinability during months of monsoon, i.e. after 12-16 months of storage. While except Dichanthium annulatum, all other five species shows sudden fall in germination rate during the months of summer, i.e. at the storage of 8-10 months.

\section{Capacity for immediate germination}

Although, for about all of the species examined, the germination of a fraction of the seed population was recorded in the initial test performed immediately after the seed collection, and the results showed that seeds of all six species seemed to be $100 \%$ dormant as they did not germinate (Fig. 1). And their dormancy exhibited up to 2-4 months of storage, though the seeds were viable. Only Apluda mutica, Cenchrus ciliaris and Dichanthium annulatum showd germination after the two months of storage while the other three species showed dormant seeds, even after the storage of two months.

\section{Response to dry storage}

The dry storage showed various effects on germination patterns in the present test system viz: generally increasing the germinability, improvement of germinability, or dormancy breaking. In all six species, storage was associated with a progressive increase in germination percentage and rate. Thus from the results, two groups can be distinguished. The first contain four species (Apluda mutica, Cenchrus ciliaris, Dichanthium annulatum and Heteropogon contortus) in which high initial germinability after the two months of storage was lowered up to $20 \%$. While the second category contains two species (Chrysopogon fulvus and Themeda triandra) in which initial high germination rate i.e. after four months of storage was increase up to 8-10 months and then after it declined to zero (Fig. 1).

Tab. 1. Dormancy/germination responses of the selected grass species

\begin{tabular}{|c|c|c|c|c|c|c|c|c|c|c|c|c|c|c|c|c|}
\hline \multirow{3}{*}{$\begin{array}{l}\text { Species } \\
\text { index }\end{array}$} & \multirow{3}{*}{ Species name } & \multirow{3}{*}{$\begin{array}{c}\text { Seed } \\
\text { collection } \\
\text { time }\end{array}$} & \multicolumn{14}{|c|}{$\%$ germination and viability at different storage durations } \\
\hline & & & & DT & IT & IT & IT & DT & DT & DT & IT & IT & IT & DT & DT & DT \\
\hline & & & & 0 & 2 & 4 & 6 & 8 & 10 & 12 & 14 & 16 & 18 & 20 & 22 & 24 \\
\hline \multirow{2}{*}{ Sp. 1} & \multirow{2}{*}{ Apluda mutica } & \multirow{2}{*}{ Oct-07 } & $\mathrm{V}$ & 40 & - & - & 75 & - & - & 90 & - & - & 100 & - & - & 60 \\
\hline & & & G & 0 & 20 & 40 & 70 & 50 & 50 & 80 & 100 & 100 & 95 & 80 & 50 & 45 \\
\hline \multirow{2}{*}{ Sp. 2} & \multirow{2}{*}{ Cenchrus ciliaris } & \multirow{2}{*}{ Feb-08 } & $\mathrm{V}$ & 44 & - & - & 92 & - & - & 96 & - & - & 100 & - & - & 96 \\
\hline & & & G & 0 & 40 & 90 & 60 & 65 & 55 & 80 & 100 & 95 & 90 & 80 & 95 & 70 \\
\hline \multirow{2}{*}{ Sp. 3} & \multirow{2}{*}{ Chrysopogon fulvus } & \multirow{2}{*}{ Dec-07 } & V & 8 & - & - & 50 & - & - & 70 & - & - & 88 & - & - & 12 \\
\hline & & & G & 0 & 0 & 20 & 40 & 10 & 20 & 50 & 40 & 30 & 20 & 0 & 0 & 0 \\
\hline \multirow{2}{*}{ Sp. 4} & \multirow{2}{*}{$\begin{array}{l}\text { Dichanthium } \\
\text { annulatum }\end{array}$} & \multirow{2}{*}{ Dec- 07} & V & 76 & - & - & 92 & - & - & 96 & - & - & 92 & - & - & 60 \\
\hline & & & G & 0 & 60 & 30 & 50 & 45 & 70 & 65 & 90 & 75 & 66 & 45 & 50 & 35 \\
\hline \multirow{2}{*}{ Sp. 5} & \multirow{2}{*}{ Heteropogon contortus } & \multirow{2}{*}{ Nov- 07} & V & 72 & - & - & 96 & - & - & 92 & - & - & 96 & - & - & 40 \\
\hline & & & G & 0 & 0 & 60 & 52 & 85 & 80 & 65 & 90 & 45 & 80 & 30 & 10 & 20 \\
\hline \multirow{2}{*}{ Sp. 6} & \multirow{2}{*}{ Themeda triandra } & \multirow{2}{*}{ Dec-07 } & $\mathrm{V}$ & 60 & - & - & 84 & - & - & 100 & - & - & 80 & - & - & 40 \\
\hline & & & G & 0 & 0 & 10 & 80 & 45 & 100 & 80 & 95 & 100 & 80 & 40 & 0 & 0 \\
\hline
\end{tabular}

IT = Increasing temperature (IT regime); DT = Decreasing temperature (DT regime); 'V'= viability \%; 'G'= germination \% 

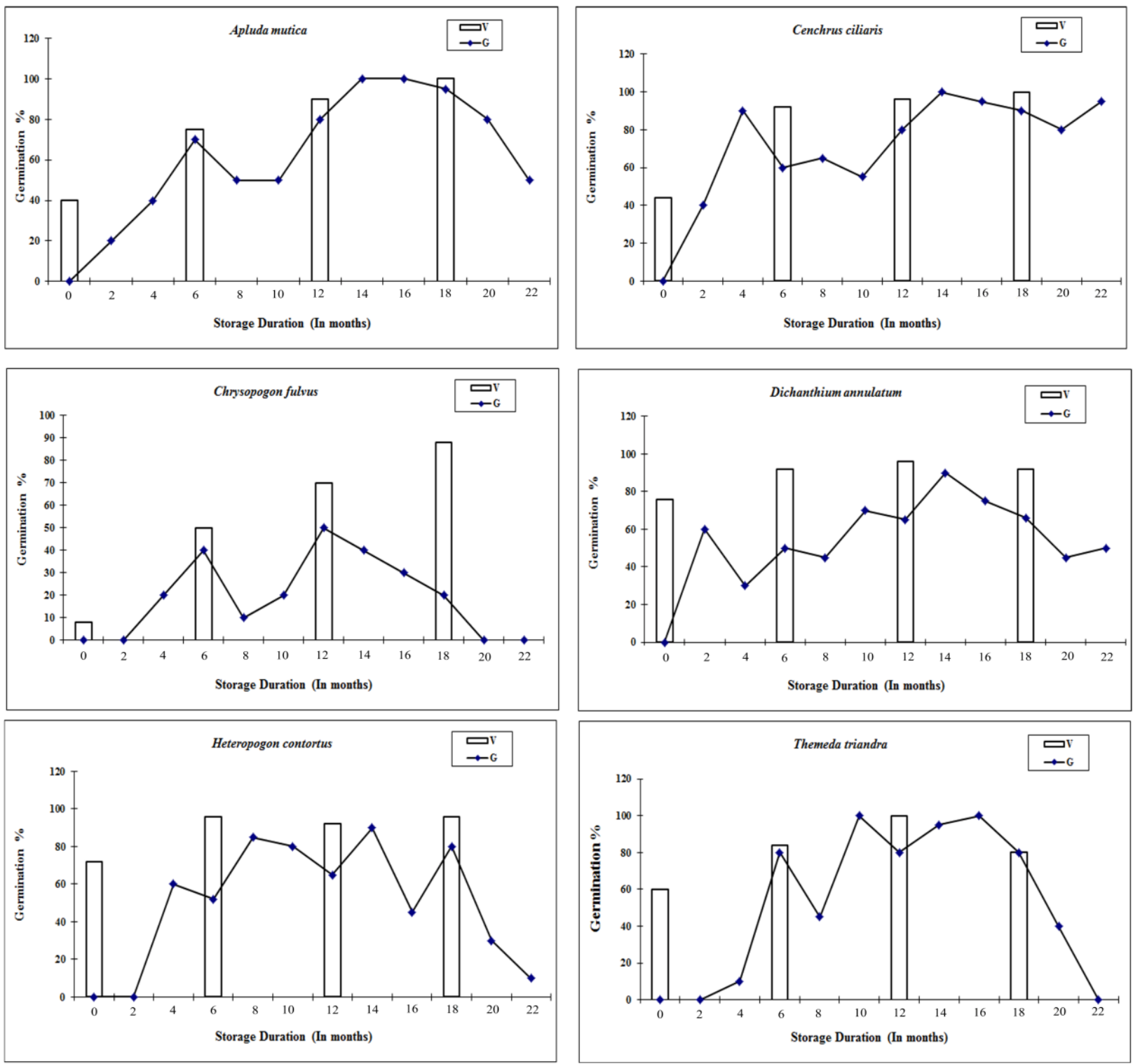

Fig. 1. Germination response against viability

\section{Response to temperature fluctuation}

The requirement of temperature fluctuation for dormancy breaking is known to be common in wetland species and arable weeds (Thompson and Grime, 1983). If a species subjected to the present screening has a low or moderate requirement for a temperature fluctuation, it would be fulfilled by the gradual change of temperature in the test system. In species with a larger requirement for temperature fluctuation, a considerable increase in germination should occur under the alternating temperature regime immediately following the IT regime. From the results we can see that each of six species showed considerable increase in germination rate as the temperature increased. But during the testing after 8-10 months of storage, some kind of fall in germination in each species was seen and that is because the environmental conditions reached at the peak of IT regime, where temperature almost reached above $40^{\circ} \mathrm{C}$. As the temperature again fall $<40^{\circ} \mathrm{C}$ seeds of each species started germinating, which actually shows the minor sensitivity to the fluctuating temperature. In present screening among all six species Apluda mutica, Cenchrus ciliaris and Dichanthium annulatum shows dependable germination pattern to fluctuating temperature.

Among grasses a high proportion of species was capable of germination over a wide range of temperature i.e. $>20^{\circ} \mathrm{C}$. This feature is particularly evident in species of dry habitats which suggests that relative insensitivity to temperature is characteristic of seed in which water supply acts as the primary determinant of the timing of germination in the laboratory condition as well as field.

Other eco-physiological parameter studied was viability testing which was done at the regular interval of six months. The correlation between viability and germination showed by the selected grass species was graphi- 

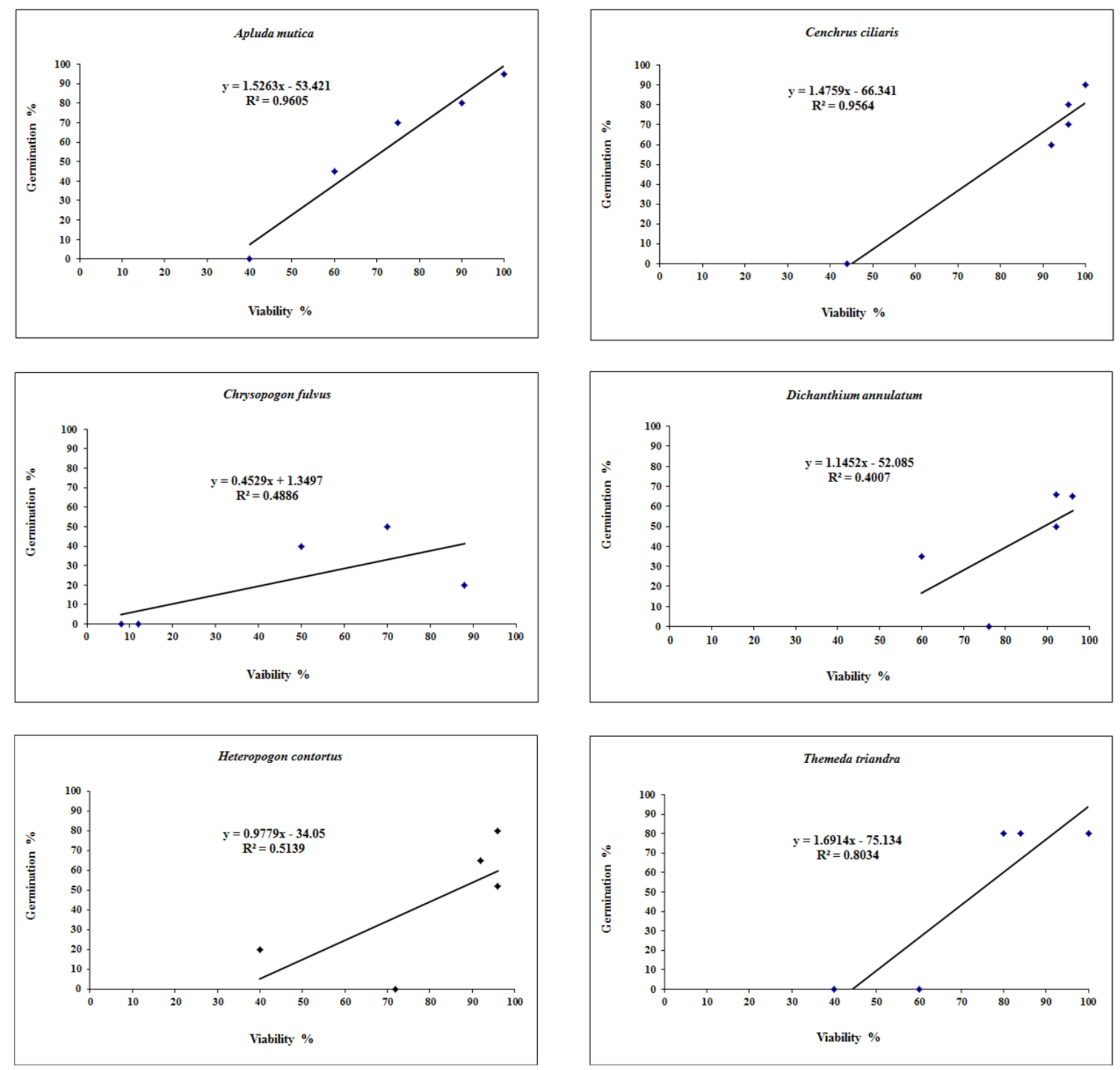

Fig. 2. Correlation between viability and germination

cally represented in the Fig. 2 and Fig. 3. Form the results we can see that the Apluda mutica, Cenchrus ciliaris and Themeda triandra shows the almost perfect positive correlation. Their germination rates are linearly dependent on viability that the seed have. They showed less influence of the relative fluctuating environmental factors. Thus, such species can be store for longer period and frequently can be use for community regeneration in pasture development. In opposite to that Chrysopogon fulvus, Dichanthium annulatum and Heteropogon contortus showed positive correlation but that was not perfect one. Thus, some kind of environmental factors put influence on their germinability that they couldn't show dependable germinability.

The experimental conditions used throughout this study were extremely simple and are comparable to the natural condition. Thus the results obtained we can apply to the natural regeneration for same seed population. The findings of the present study suggest that most of all seeds show considerable viability up to 18 months of storage. These seeds remained dormant for initial storage of 2-4 months then after they show considerable germination. In present study screening approach was adopted which is based on the following assumptions:

a. achievements in germination rate might have taken place when seed populations were transferred from field condition (in vivo) to the lab conditions (in vitro);

b. a sufficient number of species can be examined for their responses towards the different environmental factors. A species giving positive responses were identified which can be extrapolated in the field; 


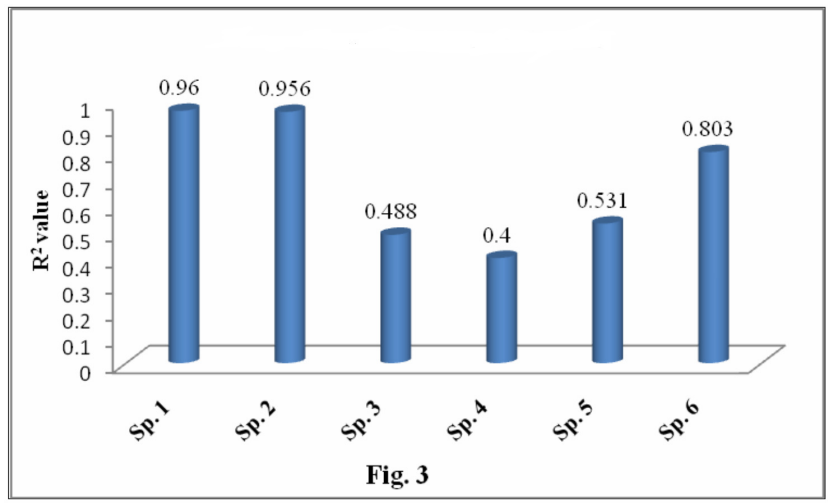

Fig. 3. Comparison of correlation Co-efficient

c. ecological importance of the seed populations that differs and often detectable in the responses.

By comparing the germination curves for IT and DT regimes and also by examining the effects of other ecophysiological parameter (viability) on the germination patterns in the test system, we could extract information on the germination characteristics of individual seed populations: the presence or absence of induction or breakage of dormancy by certain thermal (temperature) regimes, the permissible or optimal temperature range for the germination of non-dormant seeds and, the range of thermal time required for germination in different storage durations. As suggested by Geneve (2005), the secondary dormancy induced due to unfavorable an environmental condition which exhibited in results as sudden fall in the germination curve. This secondary dormancy might be induced due to effect of dry storage which has ability to alter the pattern of dormancy and germination (Dasti et al., 2001). Similar kinds of results have been reported by Bennington et al. (1991) by using the seeds of Luzula parviflora.

The results of the present study show numerous instances where the different species showing similar kind of seed characteristics reoccurs in association with species of same ecology. And such information can be used through the extrapolation in regeneration activities. It also can be a satisfactory analysis in which laboratory results are complemented by studies of production and chance of seeds under natural conditions. Such results showed by Tobe et al. (2005) in which they studied the dependence of seed germinability on the temperature, dormancy along with seed viability and precipitation available in the field condition.

Seed dormancy is an adaptation that prevents the germination of newly dispersed seed and, based on the length and type of dormancy, may help to preserve a supply of seed in the soil seed-bank. Seed growers need to understand the potential for seed-bank persistence due to seed dormancy attributes which control the timing of germination to maximize the probability of seedling survival (Tarasoff $e t$ al., 2007). With no exceptions, all selected species shows some dormancy period for about 2-4 months and then after they all shows increasing germination. As we know the fact that species which shows high initial germinability are known for seed storage by the means of seed bank. In contrast to this fact, selected species shows some dormancy period due to which the ability of persistence in any fluctuating environmental conditions will increase and seed may survive for their regeneration. Being the common and dominant; for selected species, there will be no need of seed bank for increase the production and regeneration of them.

Beneficial effects of dry storage upon germinability were most sticking for such forage species. Seeds of selected species are shed during the post monsoon. The afterripening functions as the mechanism for prevention of pre-mature germination in dry habitats. The effect of premature germination may result in the production of plants with low vigor. The species, which displayed a distinct improvement in germinability during dry storage, are small seeded. Thus, the consideration of possibility was occurred that in certain related species a major effect of delayed ripening and germination is to facilitate seed burial.

Successful seedling establishment mainly depends on the availability of temporary favorable conditions, and the prospects for survival and reproduction during later stages of the life may be affected by the speed of germination and the rate of seedling development. Therefore, it is interesting to propose that all the species are capable of rapid germination in their own natural environments, while at the same species low germination rate were observed in the present study, which arose from the failure in giving the appropriate environmental conditions to the seeds. The germination rates recorded in the initial and following series of tests, based $n$ the initiation of hydration of air dried seeds. This effect of hydration reproduces the common situations in which germination of many species, at the end of summer, match with the experimental wet conditions. Fully imbibed seeds are capable to induce germination by environmental stimuli such as changes of temperature and light. Thus, the rates of germination, recorded in the present study, may vary being achieved in the field. Such difference in germination rates with variable temperature was observed by Yuan and Shi (2009) in germination rate of S. alterniflora.

The time-course of the germination response to temperature in each species has been presented in the Tab. 1 with the reference to curve type developed in Fig. 1. All species shows almost bell shaped curve. At this type of curve, the upper limit of temperature range became constant after the initiation of germination and also shows progressive extension with time of the lower limit. The establishment of a contact between seed and substrate is a critical factor determining imbibition and germination possibility of the seed. However, during higher temperatures rapid evaporation of moisture from the substrate or the soil surface becomes a severe hazard to the seedlings which are established in response to temporary available water/moisture to the substrate. A selective advantage can 
50

be gained from the mechanism which restricts germination until the constant desirable source of moisture or low evaporating losses, or both show potential for the seedling survival. Despite of waiting for such favorable sources of environmental factors for germination, human induced supply of moisture, could also help in gaining maximum output in the field conditions.

The present study indicated that, along with temperature and dormancy, seed longevity i.e. seed viability play a crucial role in determining germinability due to which seedling establishment can be regulated in the field condition. Thus, the seed distribution of seeds in field condition is expected to determine the proportion of germination and also act to maintain seed banks over a time. Germination preference varied between genus, species even taxa. This might be resulting from differing optimum temperature required by different seed populations, intervals for germination, and dormancy strength which is also taxon specific and highly variable. These dormancy dependent germination preferences, basically explained how the taxa can perform in colder or warmer climates. In the field, an entire seed cohort will not germinate during a single season.

\section{Conclusions}

From the ecophysiological studies of seed germination we can suggest that temperature, its changes, and its fluctuation can be the most reliable environmental signals to indicate the appropriate timing for germination. Thus, for the successful community development, dry storage and timely utilization of the stored seeds, can help in community restoration mainly when there is a continual dwindling in the palatable forage resource.

\section{Acknowledgements}

We are thankful to Department of Forests, Working plan circle, Vadodara, Gujarat, India for their financial support.

\section{References}

Andrews CJ, Burrows VD (1972). Germination response of dormant seeds to low temperature and gibberellins. Can J Plant Sci 52:295-303.

Baskin JM, Baskin CC (1985). The annual dormancy cycle in buried weed seeds: a continuum. BioScience 35:492-498.

Beckstead J, Meyer SE, Allen PS (1995). Effects of afterripening on Cheatgrass (Bromus tectorum) and Squirreltail (Elymus elymoides) germination, p. 165-172. In: Proceedings: Wildland Shrub and Arid Land estoration Symposium, Las Vegas, Nevada, 19-21 Oct. 1993. USDA Frest sevice General Technical Report INT-GTR-13-315. Ogden, Utah.
Bennington C, McGraw J, Vavrek M (1991). Ecological genetic variation in seed banks, II: Phenotypic and genetic differences between young and old subpopulations of Luzula parviflora. J Ecol 79:627-644.

Dasti AA, Fatima K, Malik SA (2001). Storage time on seed dormancy and germination in ETI mutants of Arabidopsis thaliana (L.) Heynh. J Res 12(1):34-42.

Geneve R (2005). Some common misconceptions about seed dormancy. Combined proceedings, Internat Plant Propag Soc 55:9-12.

Jaiswal P, Chaudhary S (2005). Germination behavior of some trees and grasses of arid lands. Bull Nat Inst Ecol 15:201205.

Karlsson LM, Ericsson J, Milberg P (2006). Seed dormancy and germination in the summer annual Galeopsis speciosa. Weed Res 46(5):353-361.

Peters J (Ed.) (2000). Tetrazolium testing handbook. Contribution No.29. The Association of Official Seed Analysts. Loose leaf.

Silvertown JW, Dickie JB (1981). Seedling survivorship in natural population of nine perennial chalk grassland plants. New Phytol 88:555-558.

Tarasoff CS, Ball DA, Mallory-Smith CA (2007). Afterripening requirements and optimal germination temperatures for Nuttall's Alkaligrass (Puccinellia nuttalliana) and weeping Alkaligrass (Puccinellia distans). Weed Sci 55:36-40.

Thompson K, Grime JP (1983). A comparative study of germination responses to diurnally-fluctuating temperatures. J Appl Ecol 20:141-156.

Tobe K, Zhang L, Omasa K (2005). Seed germination and seedling emergence of three annuals growing on desert sand dunes in China. Ann Bot 95:649-659.

Tomado T, Schutz W, Milberg P (2002). Germination ecology of the weed Parthenium hysterophorus in eastern Ethiopia. Ann Appl Boil 140:263-270.

Washitani I (1987). A convenient screening test system and a model for thermal germination response of wild plant seeds: behavior of model and real seeds in the system. Plant Cell Environ 10:587-598.

Yuan Z, Shi F (2009). Ecological adaptation strategies in alien species: effects of salinity, temperature and photoperiod on Spartina alterniflora Loisel. seed germination. Pol J Ecol 57(4):677-684. 